\title{
A computational framework examining the mechanical behaviour of bare and polymer-covered self-expanding laser-cut stents
}

\author{
Ciara G. McKenna ${ }^{1}$ and Ted J. Vaughan ${ }^{1, *}$ \\ 1 Biomedical Engineering and Biomechanics Research Centre, School of Engineering, \\ College of Science and Engineering, National University of Ireland Galway, Galway, \\ Ireland. \\ * Correspondence: Dr. Ted Vaughan ted.vaughan@nuigalway.ie
}

Copyright: () 2021 by the authors. Submitted for possible open access publication under the terms and conditions of the Creative Commons Attribution (CC BY) license (https://creativecommons.org/license s/by/4.0/).

\begin{abstract}
:
Polymer covered stents have demonstrated promising clinical outcomes with improved patency rates compared to traditional bare-metal stents, however little is known on the mechanical implication of stent covering. In the present work, a combined experimental-computational investigation was carried out to determine the role of a polymeric cover on the biomechanical performance of self-expanding laser-cut stents. Experimental bench top tests were conducted on bare and covered versions of a commercial stent to evaluate the radial, axial and bending response. In parallel, a computational framework with a novel covering strategy was developed that accurately predicts stent mechanical performance, and provides further insight into covered stent mechanics by considering different stent geometries and polymer materials. Results show that stent covering causes increased initial axial stiffness and substantial radial stiffening at small crimp diameters as the cover folds and self-contacts. It was also shown that use of a stiffer polymeric covering material caused significant alterations to the radial and axial response, highlighting the importance of considering the mechanical properties of the combined cover and stent.
\end{abstract}

Keywords: Peripheral Stents; Polymer-covered stents; Finite Element Analysis;

\section{Introduction}

Atherosclerosis, characterised by luminal narrowing and blood flow obstruction, is the leading cause of death worldwide [1]. Endovascular stenting is a commonly used intervention for severe atherosclerosis, with an estimated three million stents implanted annually [2]. Despite their widespread use, there are several recurring clinical problems associated with stenting, including injury to the arterial wall upon implantation, in-stent restenosis [3,4], increased risk of plaque embolization, and thrombus formation [5]. In particular, stent implantation in vessels that experience high flexion remains problematic with many occurrences of stent fracture requiring high re-intervention rates [6,7]. To address complications associated with conventional bare-metal stents (BMS), a number of new endovascular stent designs have emerged, including covered stents, whereby the metallic stent is combined with a flexible polymer. These coverings are typically made from expanded polytetrafluoroethylene (ePTFE), polyurethane (PU) or polyethylene terephthalate (PET/Dacron) and 
applied to the stent frame through suturing, wrapping, dip-coating or electrospinning processes [8]. Covering a laser-cut stent replaces the open spaces between the stent struts with a polymer membrane to create a solid-walled tubular device and these have been effective in excluding aneurysms [9], preventing tumour in-growth [10], and sealing perforated vessels [11]. Covered stents also have benefits in reducing the incidence of tissue in-growth and re-embolization, as the cover acts as a mechanical barrier between the bloodstream and the vessel wall [12,13]. Importantly, covered stent configurations provide a continuous, stabilising link across the metallic frame, reducing the need for interlinking struts and thus allowing more innovative stent designs.

Current clinical research on covered stents shows improved patency outcomes and reduced incidences of re-occlusion compared to bare-metal stents in complex femoropopliteal [13-15] and iliac lesions [1619]. For example, the Viabahn Endoprosthesis (W.L. Gore and Associates, Flagstaff, Arizona) is an ePTFE covered self-expanding Nitinol stent with established safety and efficacy for peripheral artery disease treatment in long and complex regions [20]. Compared to bare-metal peripheral stents, the Viabahn device has demonstrated significantly improved patency (78.1\% versus $53.5 \%$ in a BMS), improved freedom from revascularisation (85\% versus $77 \%$ in a BMS) and reduced incidences of restenosis ( 9 cases versus 22 in a BMS) after a 12-month follow-up [13]. Similarly, for treatment of complex iliac lesions, the balloon-expandable covered Advanta V12 (Atrium Medical Corp, Hudson, $\mathrm{NH}$ ) has shown reduced incidences of restenosis at 18-months (8 cases versus 20 in the BMS group). However, despite these promising clinical results, few studies have investigated the biomechanical performance of covered stent systems, which implies that there is lack of understanding on the mechanical implication of adding a polymer cover on the overall functional performance of the device. Laser-cut stents have advanced considerably in recent times and there is now a wide variety of designs available, whose functional properties can be tailored for specific clinical applications. In particular, radial, compressive and bending behaviour can be optimised by tailoring the unit cell design (e.g. open/closed-cell) [21,22], strut width/thickness [23,24] and/or the stent material properties. Separately, polymer covering materials are evolving with improved haemocompatibility, biocompatibility and mechanical properties, and have prospects as effective drug delivery systems due to the large contact area with the luminal wall [25]. Despite the relatively low stiffness of these polymer materials compared to the stent frame itself, there is evidence that they may lead to unwanted changes in mechanical performance, which could be detrimental for the intended application. For example, a recent study on a tracheobronchial laser-cut stent system showed that the addition of a polycarbonate-urethane cover more than doubled the maximum radial force at crimp, compared to the bare-metal stent alone [26]. Our recent studies on covered braided stents showed that the addition of a cover led to substantial increases in both radial and axial stiffness, by altering the fundamental deformation mechanisms involved in these wire-based stent configurations $[27,28]$. Other studies on the mechanics of covered stents are limited, with research in this area mainly focussing on large stent-grafts with separated wire rings intended for abdominal artery aneurysms [29-32]. Given that covered stent systems are providing promising clinical results across a range of applications, there is a clear need to develop a thorough understanding of their mechanics as we aim for a biometric design capable of accommodating arterial deformation [33]. 
This study presents a combined experimental-computational investigation into the role of a polymer cover on the biomechanical performance of self-expanding laser-cut stents. Firstly, a detailed experimental evaluation of the biomechanical properties of the open-cell Precise Pro (Cordis Endovascular, a Johnson \& Johnson company, Miami, FL) stent is presented, whereby the radial, axial and bending response of both bare-metal and polymer-covered versions of the stent are determined. In parallel, a validated computational framework is developed that enables accurate predictions of the mechanical performance of this polymer-covered stent system. This computational framework is then used to provide further insight into covered stent mechanics by considering a range of unit-cell designs (i.e. closed-cell and separated z-rings) and polymer cover properties.

\section{Materials and Methods}

\subsection{Experimental Testing}

The mechanical response of bare and covered laser-cut self-expanding stents was evaluated experimentally by conducting radial compression, axial compression and bending tests. This test sequence was performed on two bare-metal stents, then the stents were covered and the test sequence was repeated.

\subsubsection{Stent Geometry}

Experimental testing was carried out on Precise Pro open-cell laser-cut stents (Cordis Endovascular, a Johnson \& Johnson company, Miami, FL), shown in Figure 1 (a). Each stent had an outer diameter of $7.2 \mathrm{~mm}$, a length of $30 \mathrm{~mm}$ and a strut thickness of $200 \mu \mathrm{m}$. The stents were covered through a wrapping/forming process, whereby a polyurethane-polytetrafluoroethylene (PU-PTFE) composite polymer membrane was applied on both the interior lumen and the adluminal stent surfaces in a sandwich-like configuration. Each layer had a thickness of $12.5 \mu \mathrm{m}$, so the cover thickness between the stent struts was $25 \mu \mathrm{m}$. A fully covered stent is shown in Figure 1 (b).
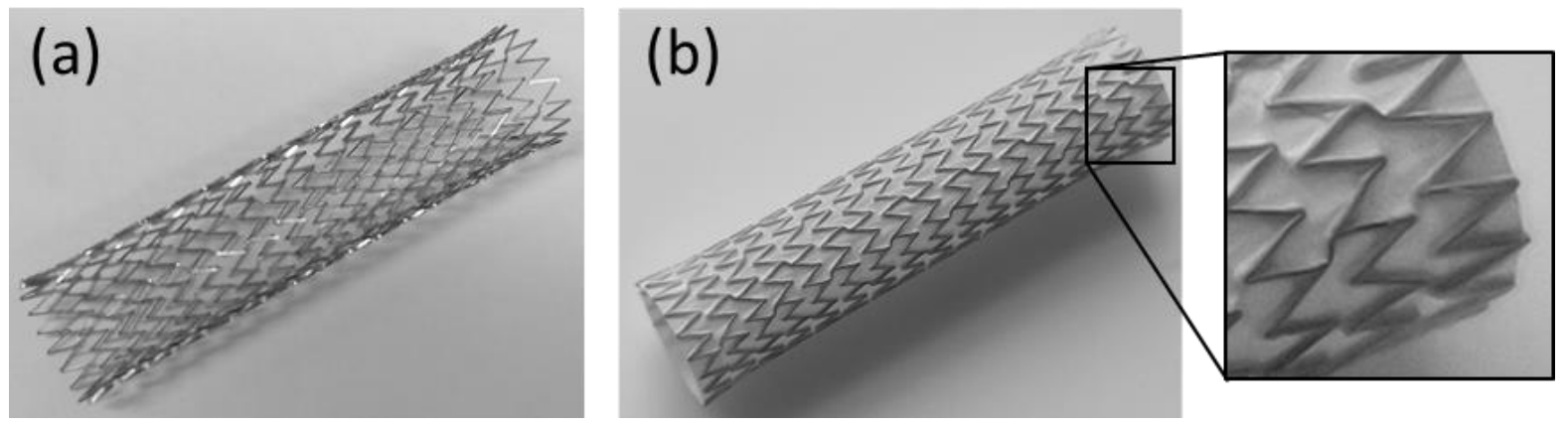

Figure 1: (a) Bare-metal Precise Pro stent (Cordis Endovascular, a Johnson \& Johnson company, Miami, FL), and (b) its covered counterpart. Inset shows the cover on lumen and adluminal stent surfaces.

\subsubsection{Radial Compression}

Radial force testing was carried out at $37^{\circ} \mathrm{C}$ using an 8-plate crimping head (RCM-H60, MPT Europe) connected to a Zwick uniaxial test machine with a 100N load cell (Zwick Roell, GmbH \& Co., Germany). Each test was performed with a plate displacement rate of $0.1 \mathrm{~mm} / \mathrm{s}$. The bare-metal stents were crimped from their expanded diameter of $7.2 \mathrm{~mm}$ to a crimped diameter of $2 \mathrm{~mm}$, while the covered stents were sequentially crimped to $4 \mathrm{~mm}, 3 \mathrm{~mm}, 2.33 \mathrm{~mm}$ and $2 \mathrm{~mm}$. The covered stents were left in their original 
configuration for at least five minutes between each test. From the resulting force-displacement data, frictional effects were removed and then the data was converted to a radial system with radial forcediameter data. The radial response was normalised to the original stent length. The force required to crimp the stent indicates the radial resistive force (RRF), while the force generated during stent expansion indicates the chronic outward force (COF). The initial radial stiffness was measured as the secant modulus to a crimped diameter of $6 \mathrm{~mm}$.

\subsubsection{Axial Compression}

Axial compression was performed on each stent using a Zwick uniaxial test machine with a $10 \mathrm{~N}$ load cell (Zwick Roell, GmbH \& Co., Germany) at a displacement rate of $0.5 \mathrm{~mm} / \mathrm{s}$. Each end of the stent was secured with cylindrical supports and spring clamps, described previously in [27], with a grip-to-grip separation of $25 \mathrm{~mm}$. The bottom support was fixed, while the top support was displaced downwards by $5 \mathrm{~mm}$ to compress the stent to $20 \%$ strain (see Figure 2 (b)).

\subsubsection{Bending Behaviour}

To evaluate the bending behaviour of bare and covered open-cell Precise Pro stents (Cordis Endovascular, a Johnson \& Johnson company, Miami, FL), each stent was held at a $90^{\circ}$ bend. The stent was again secured with cylindrical supports at each end and the ends were fixed into tight fit holes, while the central portion of the stent was free to deform by bending. The resulting deformation was observed.

(a)
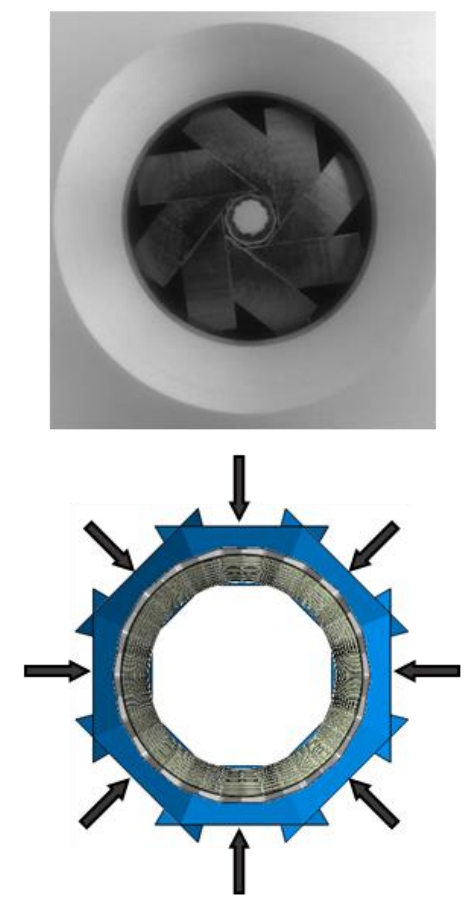

(b)
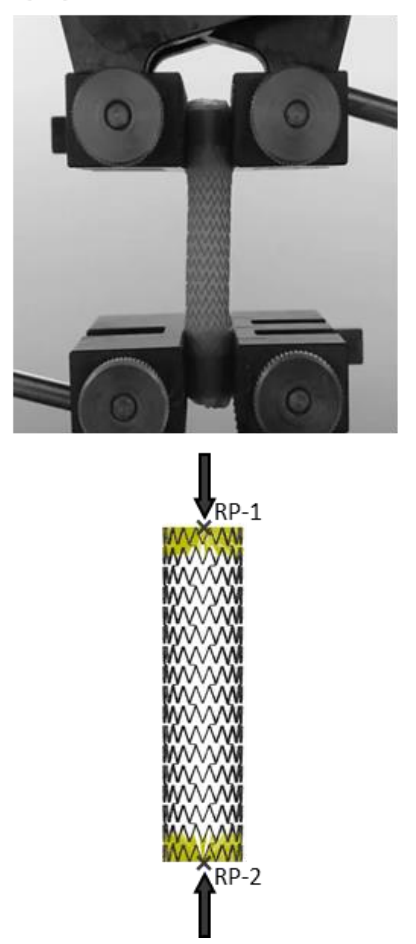

(c)
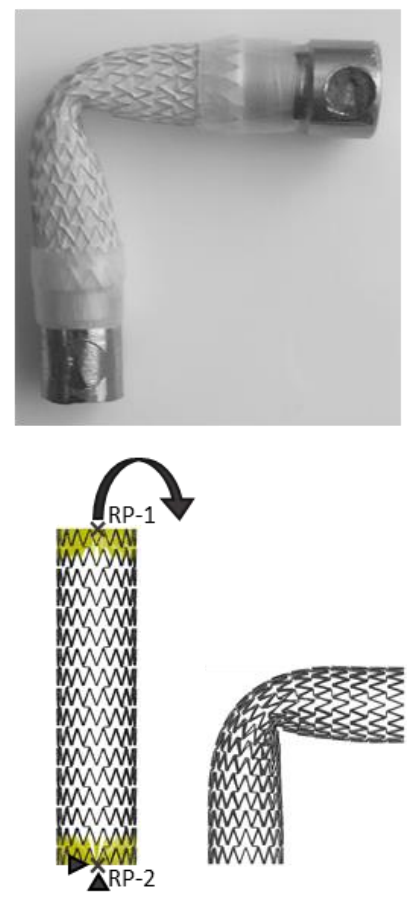

Figure 2: Experimental and computational test setup for (a) radial compression, (b) axial compression, and (c) bending. 


\subsection{Stent Computational Modelling}

\subsubsection{Stent Geometry}

Three bare-metal stents were created in Abaqus with geometries that differed only in interconnecting struts. The open-cell stent was based on the experimentally tested Precise Pro stent (Cordis Endovascular, a Johnson \& Johnson company, Miami, FL), where dimensions were obtained from analysing microscope images with ImageJ image processing software. The stent consisted of 17 interconnected rings with an outer diameter of $7.2 \mathrm{~mm}$, comprising a total length of $30 \mathrm{~mm}$. Each strut had a rectangular cross-sectional profile with dimensions $93 \mu \mathrm{m} \times 200 \mu \mathrm{m}$ (width $\times$ thickness), while the interconnecting segments had a cross-sectional profile with dimensions $60 \mu \mathrm{m} \times 200 \mu \mathrm{m}$. A repeating segment of the stent was drawn in Abaqus, meshed, bilinearly patterned and then wrapped into a cylindrical coordinate system to create a fully expanded stent geometry. This design was modified to create a closed-cell stent with interconnecting struts on each crown and a separated z-ring stent with no interconnecting struts, shown in Figure 3. Each stent was meshed with at least 470,000 eight-noded linear brick (C3D8R) elements with enhanced hourglass control.

(a)

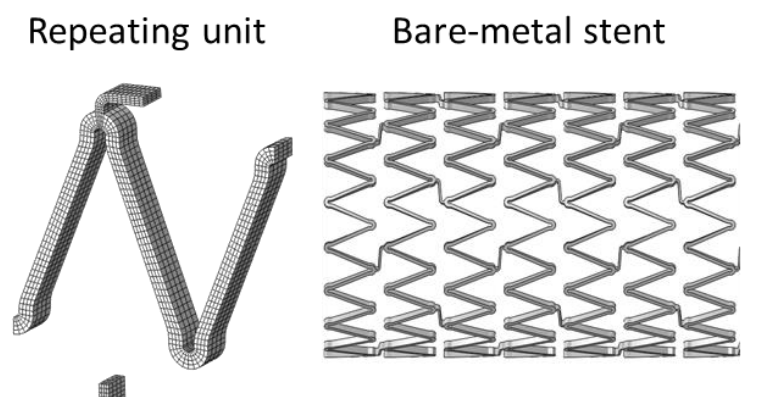

(b)
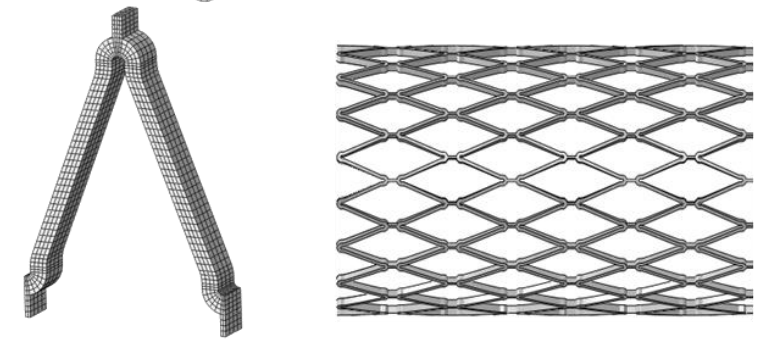

(c)

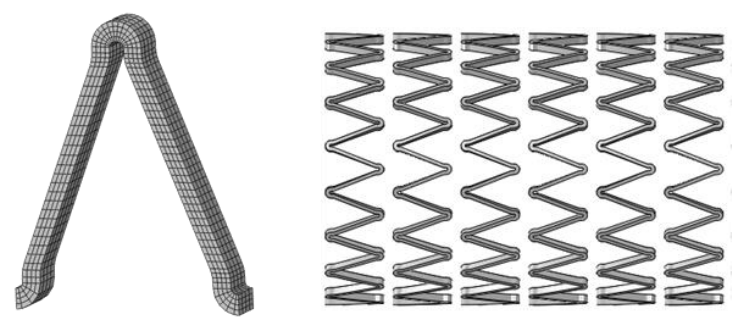

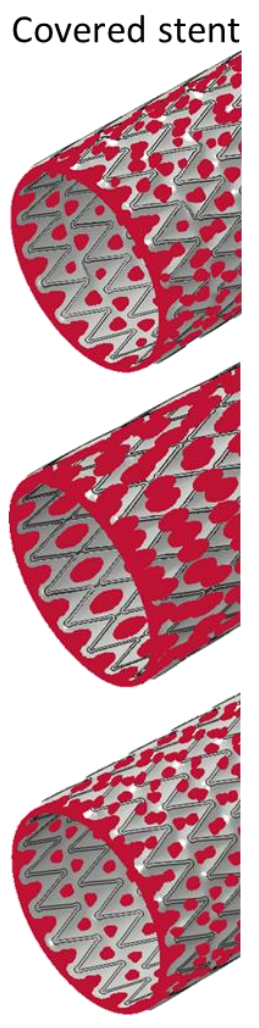

Figure 3: Stent geometries of the three stent designs analysed in this study, where (a) has an open-cell design, (b) has a closed-cell design and (c) has separated z-rings. Note that the red areas in the covered stents represent tie locations.

\subsubsection{Stent Covering}

Covered stents were simulated by replicating the covering process, whereby the stent was wrapped with inner and outer polymer covers in a sandwich-like configuration. Each cover wrap had a shell thickness of $12.5 \mu \mathrm{m}$ and was slightly longer than the stent $(31 \mathrm{~mm})$ with tapered ends. The cover 
geometry was meshed with 1,502,846 shell (S4R) elements with enhanced hourglass control. In the covering step, a small pressure load was applied to the inner $(2.5 \mathrm{kPa})$ and outer $(5 \mathrm{kPa})$ covers so that the covers contacted between struts, shown in Figure 4. The resulting covered stent geometry was exported in a stress-free state, and stent/cover adhesion assumed by implementing a Tie constraint between the inner and outer covers, where tied areas are shown in red in Figure 3.

(a)

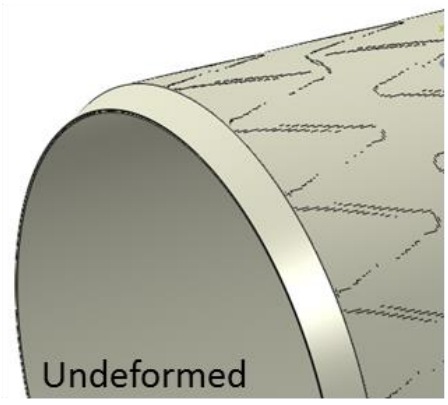

(b)

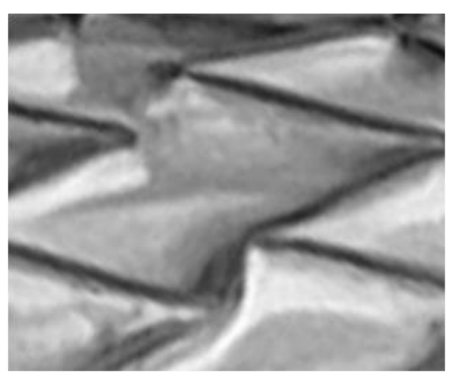

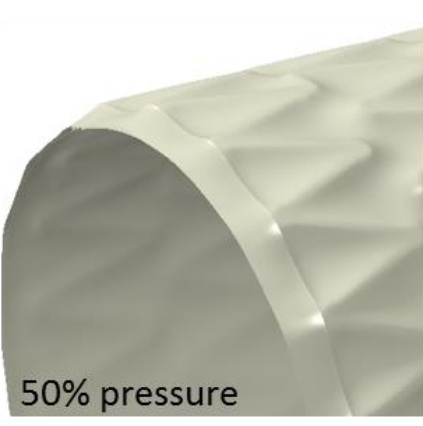
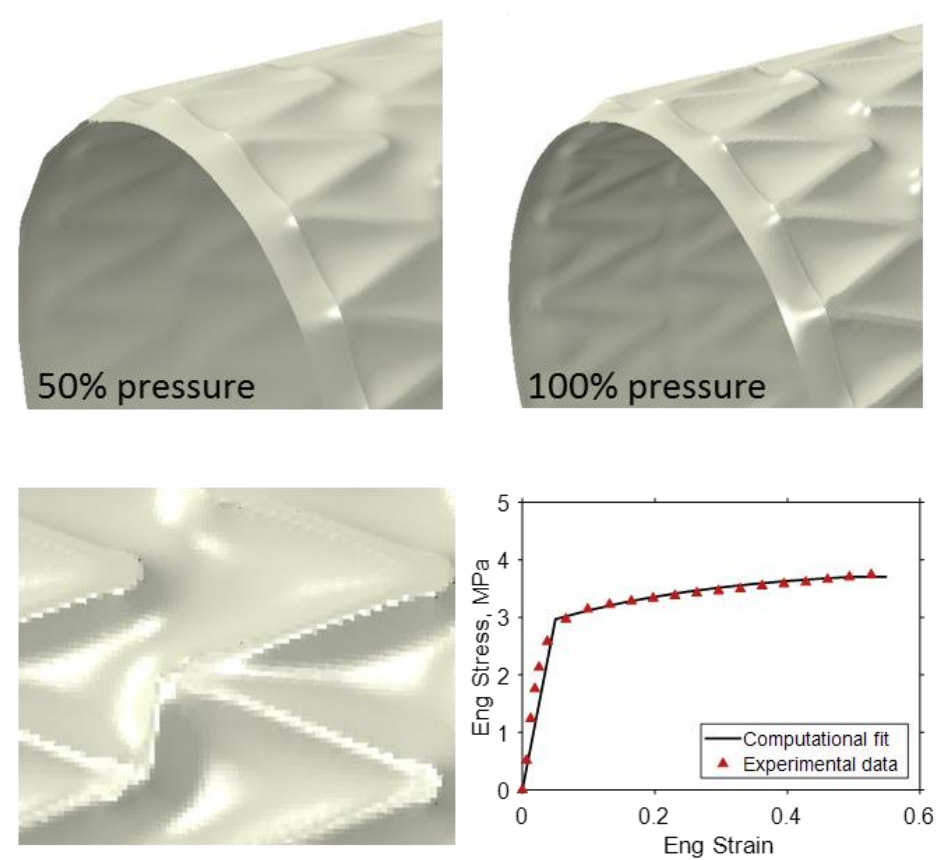

Figure 4 Detail of the stent covering simulation where (a) shows the cover deformation throughout the simulation and (b) compares experimental and computational covered stent profiles and the uniaxial tensile material response.

\subsubsection{Material Properties}

Nitinol material properties were assigned to each stent using the in-built constitutive model for superelasticity [34]. Nitinol parameters, given in Table 1, were calibrated based on the experimental radial force and axial compression response. Material properties for the polymer cover were obtained from tensile testing a thin strip sample of the PU-PTFE composite polymer at room temperature. A sample with dimensions of $100 \mathrm{~mm} \times 17.5 \mathrm{~mm} \times 0.05 \mathrm{~mm}$ (length $\mathrm{x}$ width $\mathrm{x}$ thickness) was tested under uniaxial loading at $10 \mathrm{~mm} / \mathrm{min}$ using a Zwick uniaxial test machine in conjunction with a $10 \mathrm{~N}$ load cell (Zwick Roell, GmbH \& Co., Germany). The PU-PTFE polymer behaviour can be approximated as an elasticplastic material with an elastic modulus of 91MPa and a yield stress of 3MPa, as shown in Figure 4 (b). The effect of a stiffer covering material with properties in the range of polyethylene terephthalate (PET, Dacron) was also analysed (elastic modulus of 910MPa, yield stress of 40MPa) [35].

Table 1 Nitinol material parameters used in the Abaqus constitutive model.

\begin{tabular}{rll}
\hline Symbol & Parameter & Value \\
\hline $\mathrm{EA}_{\mathrm{A}}$ & Austenite elasticity (MPa) & 45,000 \\
VA & Austenite Poisson's ratio & 0.3
\end{tabular}




\begin{tabular}{lll} 
EM & Martensite elasticity (MPa) & 30,000 \\
$\mathrm{VM}$ & Martensite Poisson's ratio & 0.3 \\
$\varepsilon \mathrm{L}$ & Transformation strain & 0.05 \\
$\sigma \mathrm{L}^{\mathrm{S}}$ & Start of transformation loading $(\mathrm{MPa})$ & 400 \\
$\sigma \mathrm{L}^{\mathrm{E}}$ & End of transformation loading $(\mathrm{MPa})$ & 330 \\
$\sigma \mathrm{U}^{\mathrm{S}}$ & Start of transformation unloading $(\mathrm{MPa})$ & 120 \\
$\sigma \mathrm{U}^{\mathrm{E}}$ & End of transformation unloading $(\mathrm{MPa})$ & 100 \\
$\sigma \mathrm{CL}^{\mathrm{S}}$ & Start of transformation stress during compression loading $(\mathrm{MPa})$ & 330 \\
$\varepsilon \mathrm{V}^{\mathrm{L}}$ & Volumetric transformation strain & 0.05 \\
\hline
\end{tabular}

\subsubsection{Model Formulation and Boundary Conditions}

Radial compression, axial compression and bending were simulated using Abaqus/Explicit v6.14 (SIMULIA, Dassault Systèmes). To ensure that dynamic effects were negligible, the ratio of kinetic energy to internal energy was kept below $5 \%$ after initial contact between the stent and rigid surfaces. In each simulation, general contact using a penalty contact method and a friction coefficient of 0.2 was defined between all contacting surfaces (e.g. stent, cover, plates).

\section{Radial Compression}

Radial compression was simulated by placing the stent in the centre of eight rigid body plates, shown in Figure 2 (a). The plates were displaced radially inwards with a smooth step amplitude to crimp the stent and then allow it to expand back to its original diameter. The radial force response of the stent was determined from the sum of the axial forces on the eight plates. The hypothetical situation of a stent composed of separate z-rings was also evaluated by simulating radial compression of a single ring and scaling the resulting force to account for the entire stent length.

Axial Compression

To replicate the experimental axial compression setup, a $2.5 \mathrm{~mm}$ longitudinal section at each end of the stent was coupled to a corresponding reference point at each end of the stent. Equal and opposite $2.5 \mathrm{~mm}$ displacements were applied longitudinally through each reference point, with all other directional and rotational boundary conditions fixed, to result in $20 \%$ compression of the unconstrained portion of the stent. The resulting axial force is evaluated from the reference point.

\section{Bending Behaviour}

The bending behaviour of bare and covered stents was simulated by applying a rotation of $90^{\circ}$ to one end of the stent, while the other end is held fixed. Similar to the axial compression model above, boundary conditions were applied through a reference point coupled to a $2.5 \mathrm{~mm}$ longitudinal section at the end of the stent. 


\section{Results}

3.1 Experimental Results and Model Validation

Experimental and computational radial force results for bare and covered open-cell Precise Pro stents (Cordis Endovascular, a Johnson \& Johnson company, Miami, FL) show excellent agreement (Figure 5). The experimental results in Figure 5(a) show that the addition of a polymer cover resulted in approximately 1.1 times greater RRF between crimp diameters of $6 \mathrm{~mm}$ and $3 \mathrm{~mm}$ for the first three radial compression cycles. The differences in radial response between bare and covered stent systems became particularly prominent at small crimp diameters, where RRF increases of 39\% and $60 \%$ were observed in covered stents at crimp diameters of $2.33 \mathrm{~mm}$ and $2 \mathrm{~mm}$ respectively (see Table 2). Otherwise, the RRF and COF were largely similar between bare-metal and covered stent systems.

There is a notable decrease in the radial force response for the covered configuration in the final radial compression cycle to a crimp diameter of $2 \mathrm{~mm}$ (Figure 5 (a)). Here, the computational model provides additional insight into the change in radial response that occurs experimentally with consecutive radial compression cycles. Computationally, the radial response of covered stents is accurately predicted for the initial compression cycles when it is assumed that a cylindrical cover is completely bonded to the outer surface of the stent, implemented with a "Tie" constraint between the stent and cover, as shown in red in Figure 5 (b). Meanwhile, the final radial compression cycle is predicted by assuming loosening of the adhesive bond, where the experimental covering process is represented more accurately with inner and outer covers in a sandwich configuration and tied bonds only between the inner and outer covers (Figure 5 (c)). Here, the computational model accurately captures the radial stiffening that occurs at small crimp diameters, with the model identifying that this is caused by self-contact of the polymer cover as it folds over on itself at full crimp. Aside from the stiffening behaviour seen in covered stents at small diameters $(<3 \mathrm{~mm})$, the computational model predicts similar RRF and COF for bare-metal and covered stent systems, as shown in Table 2. 
(a)

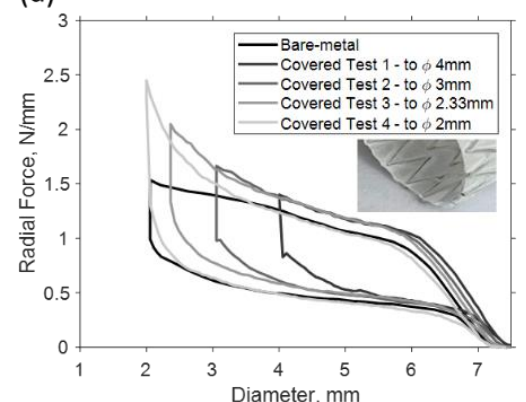

(b)

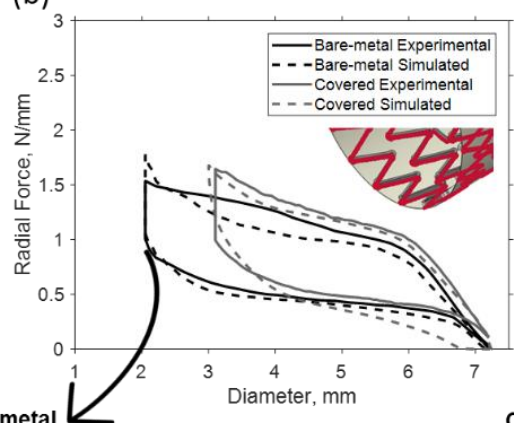

(c)

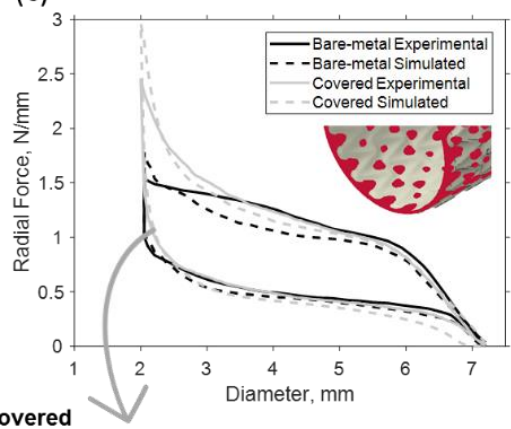

Covered
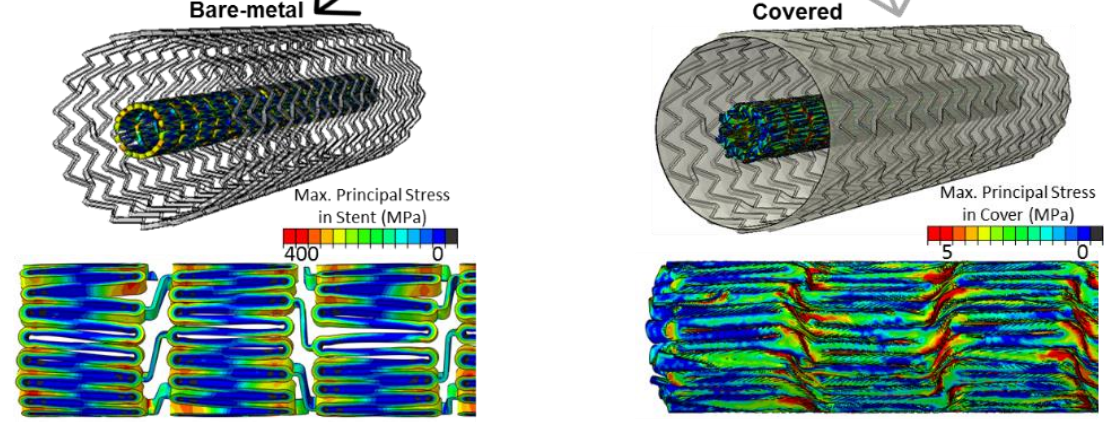

Figure 5 (a) Experimental radial compression response for bare-metal and covered Precise Pro stents, where the bare stents were crimped to a diameter of $2 \mathrm{~mm}$ and the covered stents were crimped to diameters of $4 \mathrm{~mm}, 3 \mathrm{~mm}$, $2.33 \mathrm{~mm}$ and $2 \mathrm{~mm}$ consecutively. (b) Computational results show that a cylindrical cover with attachment represented with a tie constraint between the cover and stent results in good agreement to the second radial test conducted, while (c) shows that a "sandwiched" cover with attachment represented by a tie between inner and outer covers results in good agreement to the final crimp to $2 \mathrm{~mm}$ diameter.

Table 2 Comparison of bare-metal and covered Precise Pro stents in terms of key radial response parameters; initial radial stiffness, radial resistive force $(\mathrm{RRF})$ and chronic outward force $(\mathrm{COF})$, with experimental and computational values given.

\begin{tabular}{ccccc}
\hline & \multicolumn{2}{c}{ Bare-metal } & \multicolumn{2}{c}{ Covered } \\
\hline $\begin{array}{c}\text { Initial radial stiffness } \\
\text { (per unit length) }\end{array}$ & Experimental & Computational & Experimental & Computational \\
$\quad(\mathrm{N} / \mathrm{mm} / \mathrm{mm})$ & 0.729 & 0.657 & 0.681 & 0.684 \\
$\mathrm{RRF}$ at $5 \mathrm{~mm}(\mathrm{~N} / \mathrm{mm})$ & 1.066 & 0.980 & 1.039 & 1.029 \\
$\quad \begin{array}{c}\text { Max radial force } \\
\quad(\mathrm{N} / \mathrm{mm})\end{array}$ & 1.535 & 1.730 & 2.449 & 2.965 \\
$\mathrm{COF}$ at $5 \mathrm{~mm}(\mathrm{~N} / \mathrm{mm})$ & 0.433 & 0.393 & 0.411 & 0.344 \\
\hline
\end{tabular}

Considering that these covered stents are first radially compressed (as is also the case in vivo), it is reasonable to assume a loosened cover configuration with inner and outer covers tied for all subsequent tests. Results show that this computational model accurately predicts the behaviour of bare-metal and covered open-cell stents under axial compression (Figure 6 (a)) and bending (Figure 6 (b)). Covered stents have a stiffer axial response compared to their bare-metal counterpart, with the maximum experimentally observed axial compressive force 1.6 times greater for a covered stent compared to a bare-metal stent. In terms of bending deformation, experimental and computational results show that a covered stent exhibits a greater reduction in cross-sectional area compared to a bare-metal stent at a $90^{\circ}$ bend angle. 
(a)

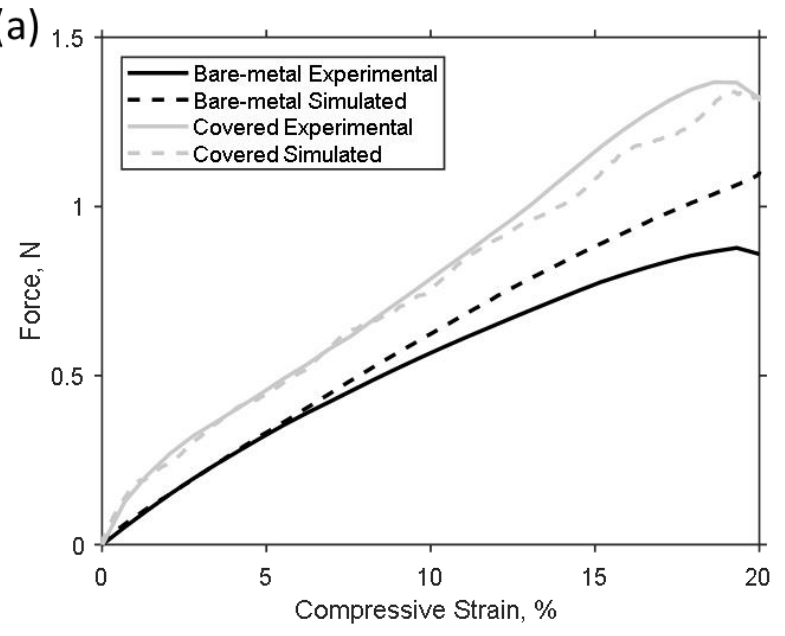

(b)

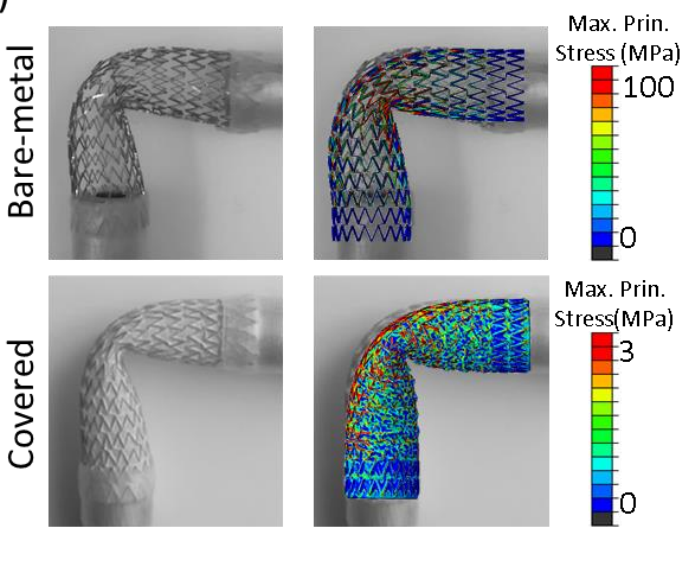

Figure 6 Experimental and computational response of bare-metal and covered Precise Pro stents under (a) axial compression and (b) bending. These tests were experimentally tested after radial compression, so for validation purposes, cover attachment is simulated with a tie between inner and outer covers.

\subsection{Radial Compression}

Simulated radial compression results for stents with open-cell, closed-cell and separated z-rings geometries are summarised in Figure 7. The results show that geometrical alterations in interconnecting struts do not have a substantial effect on the radial response. For each geometry investigated, the addition of a cover causes an increase in radial force, particularly at small diameters $(<3 \mathrm{~mm})$ where, again, there are large amounts of self-contact in the cover and contact between the stent and cover observed. The angled interconnecting strut segments in the covered open-cell stent causes more cover/cover and stent/cover contact at low crimp diameters, resulting in the highest maximum radial force $(3.03 \mathrm{~N} / \mathrm{mm})$ and the highest cover stress concentrations in the region of the interconnecting segments (see Figure 7 (a)). 


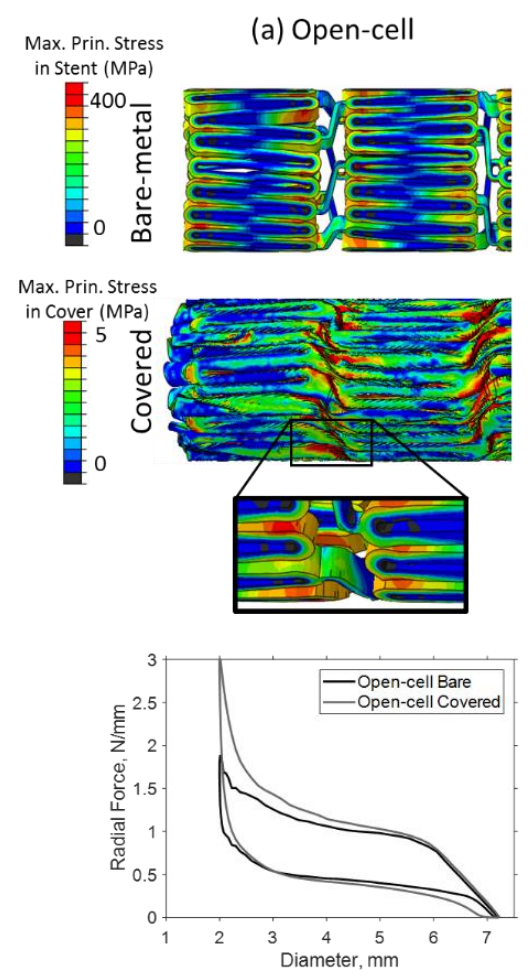

(b) Closed-cell
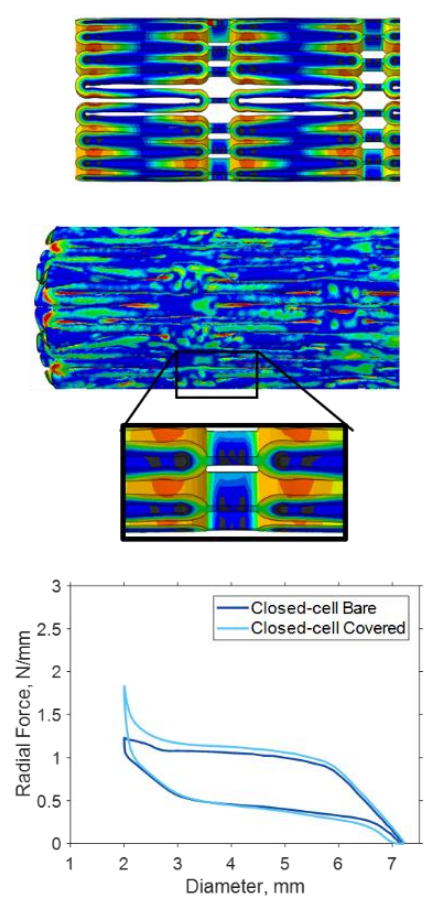

(c) Separated Z-Rings
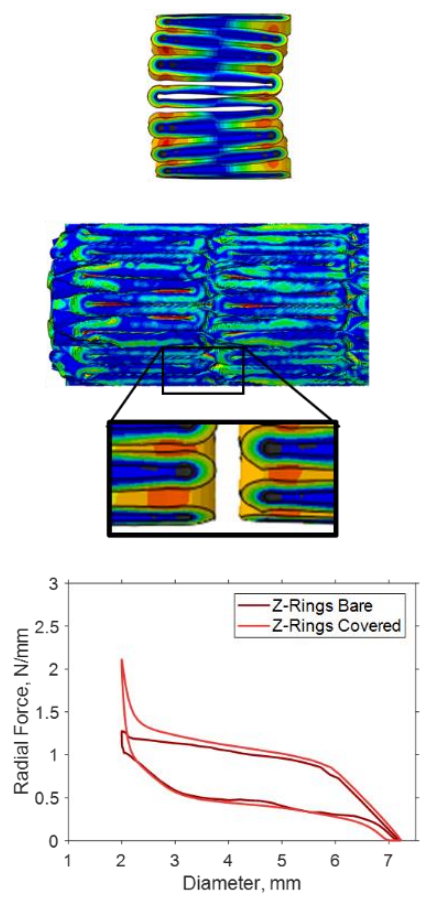

Figure 7: Simulated radial force behaviour for bare-metal and covered stents with (a) an open-cell Precise Pro geometry, (b) a closed-cell geometry and (c) a separated z-rings geometry.

\subsection{Axial Compression}

The deformation and maximum principal stress distribution in covered stents after axial compression is shown in Figure 8. The open-cell stent accommodates axial deformation by shifting the stent segments into the free cell areas, which necessitates some bending of the interconnecting struts and therefore causes stress concentrations at the interconnecting struts and their adjacent struts. The large number of interconnecting segments in the closed-cell stent increase the axial rigidity, so deformation is achieved by an outward bulging of a large portion of the stent while generating high maximum principal stresses in both the stent and the cover. Meanwhile, axial compression of the covered stent with separated z-rings is predominantly accommodated by folding of the polymer cover, with only low levels of stress in the stent. The axial stiffness of each stent varied considerably, with initial axial stiffness values (up to $1 \%$ compression) of $0.80 \mathrm{~N} / \mathrm{mm}, 92.3 \mathrm{~N} / \mathrm{mm}$ and $0.56 \mathrm{~N} / \mathrm{mm}$ for covered versions of the open-cell stent, closed-cell stent and separated z-rings stent respectively. 

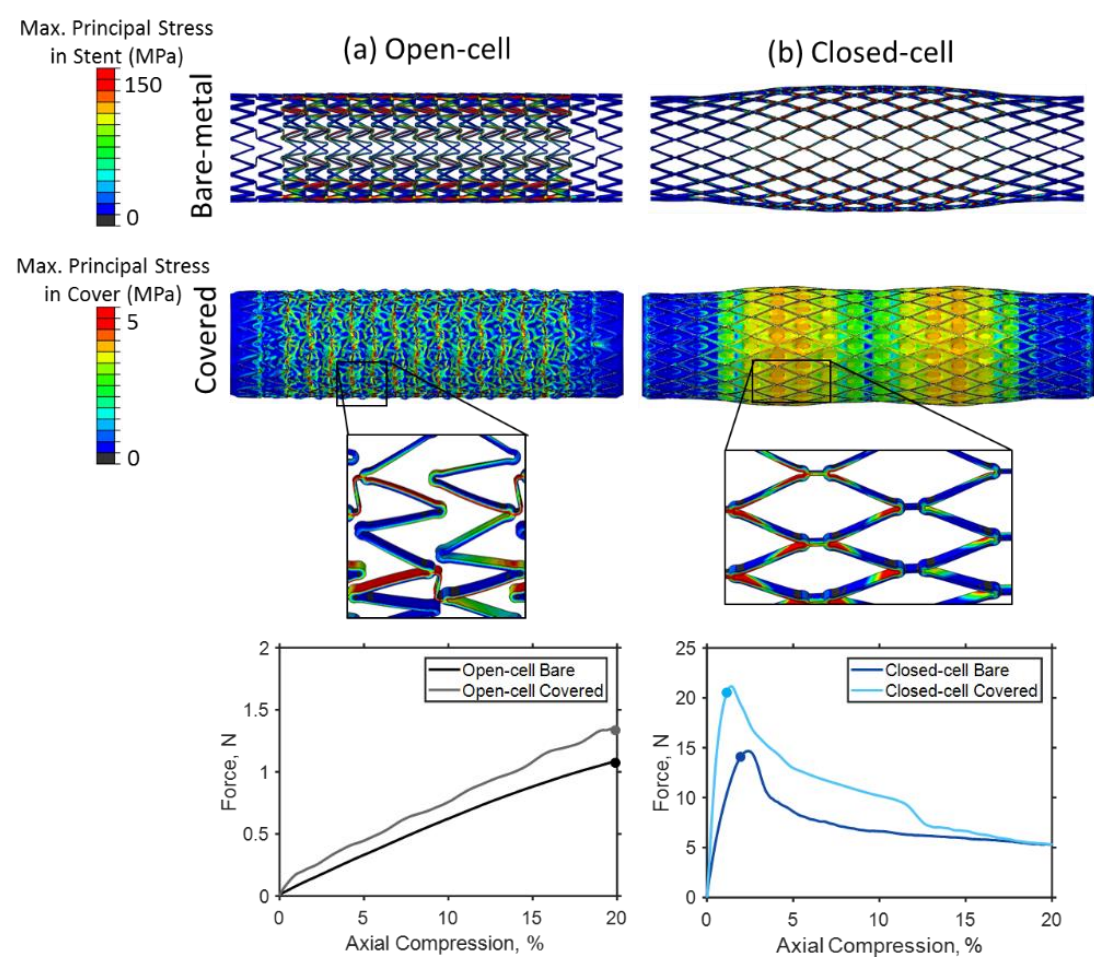

(c) Separated Z-rings
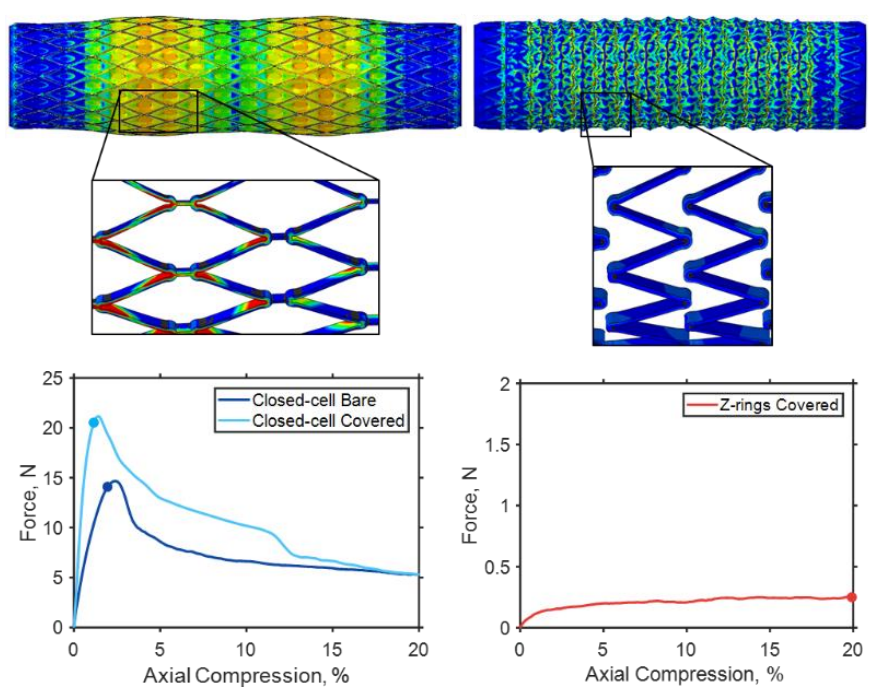

Figure 8: Maximum principle stress contour plots and axial force during axial compression of bare-metal and covered stents with (a) open-cell Precise Pro, (b) closed-cell and (c) separated z-ring geometries. Note that the contour plot images represent deformation at the buckling point for the closed-cell stent, indicated by markers on the force curves.

\subsection{Bending Behaviour}

Bending deformations of all stent geometries evaluated in this study are presented in Figure 9. Bare and covered versions of the closed-cell stent kink upon bending and show the largest stress concentrations, while the stent composed of separated z-rings accommodates bending without kinking and with little reduction in the lumen cross-sectional area.

(a) Open-cell
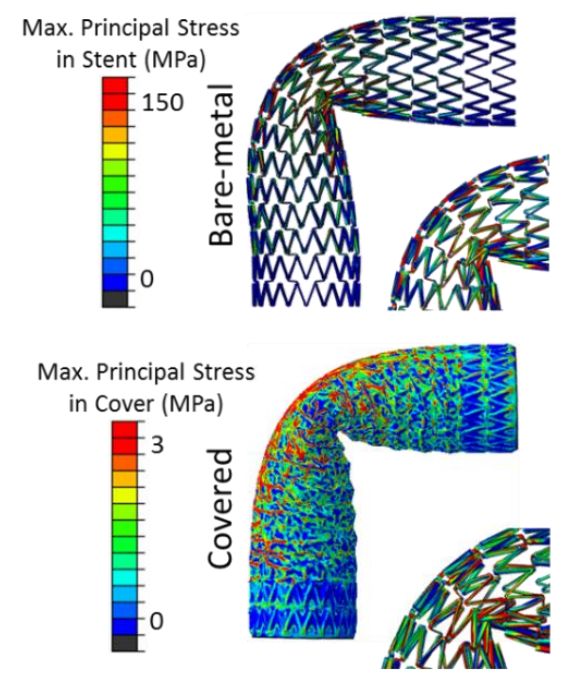

(b) Closed-cell
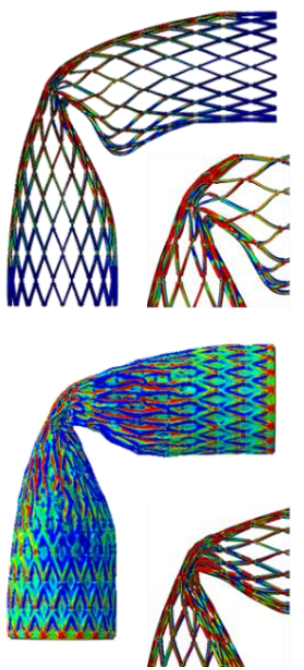

(c) Separated Z-rings

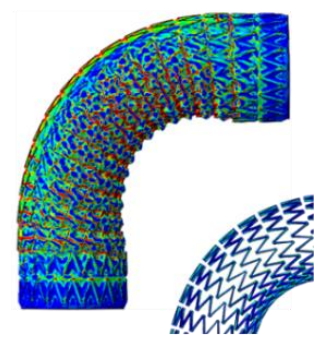

Figure 9 Bending deformations and maximum principal stress in bare-metal and covered laser-cut stents with (a) an open-cell Precise Pro geometry, (b) a closed-cell geometry and (c) a separated z-ring geometry. 


\subsection{Effect of Cover Properties}

The effect of a stiffer polyethylene terephthalate (PET, Dacron) cover was evaluated on the open-cell Precise Pro stent (Cordis Endovascular, a Johnson \& Johnson company, Miami, FL). The radial, axial and bending responses of stents covered with a PET polymer (elastic modulus $=910 \mathrm{MPa}$ ) was compared to stents covered with a PTFE-PU polymer (elastic modulus =91MPa), shown in Figure 10 . The results show that the radial response of the PET-covered stent was considerably stiffer compared to the PTFE-PU-covered stent, with increased initial radial stiffness and RRF throughout the crimp cycle (Figure 10 (a)). This increased stiffness became more pronounced at small diameters, where the PETcovered stent resulted in 1.7 times greater RRF at a crimped diameter of $2 \mathrm{~mm}$ compared to the PTFEPU-covered stent. However, upon un-crimping, the chronic outward forces across the bare and both covered configurations are largely similar. Results show that radial crimping of the covered stents caused permanent deformation, particularly in the PET-covered stent. Under axial compression, the PET-covered stent also had a stiffer response with an initial axial stiffness (up to $1 \%$ compression) of $4.7 \mathrm{~N} / \mathrm{mm}$, representing a six-fold increase in stiffness compared to the PTFE-PU covered stent. The bending deformation between the two covered stents was relatively unchanged, however greater stress was observed in the cover of the PET-covered stent.

(a)

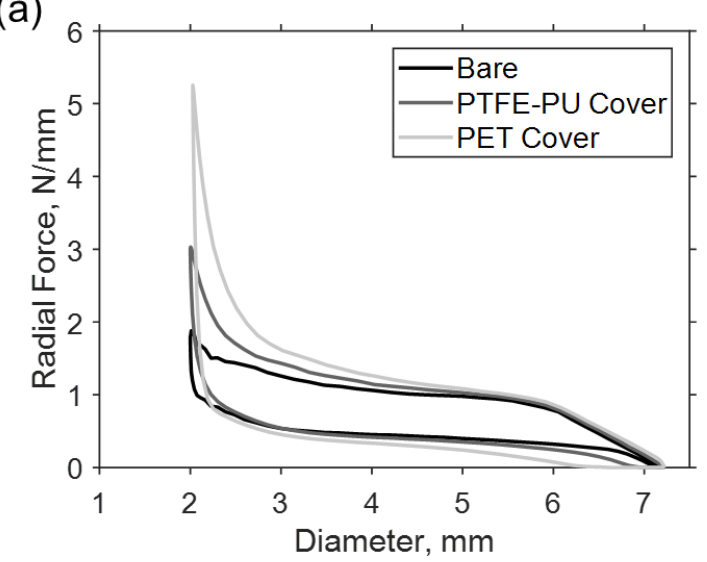

\begin{tabular}{|l|c|c|}
\hline & $\begin{array}{c}\text { PTFE-PU } \\
\text { cover }\end{array}$ & $\begin{array}{c}\text { PET } \\
\text { cover }\end{array}$ \\
\hline $\begin{array}{l}\text { Initial radial stiffness } \\
(\mathrm{N} / \mathrm{mm} / \mathrm{mm})\end{array}$ & 0.684 & 0.719 \\
\hline RRF at $6 \mathrm{~mm}(\mathrm{~N} / \mathrm{mm})$ & 0.821 & 0.863 \\
\hline RRF at $5 \mathrm{~mm}(\mathrm{~N} / \mathrm{mm})$ & 1.029 & 1.081 \\
\hline RRF at $2.2 \mathrm{~mm}(\mathrm{~N} / \mathrm{mm})$ & 2.178 & 3.440 \\
\hline RRF at $2 \mathrm{~mm}(\mathrm{~N} / \mathrm{mm})$ & 3.030 & 5.114 \\
\hline
\end{tabular}

(b)

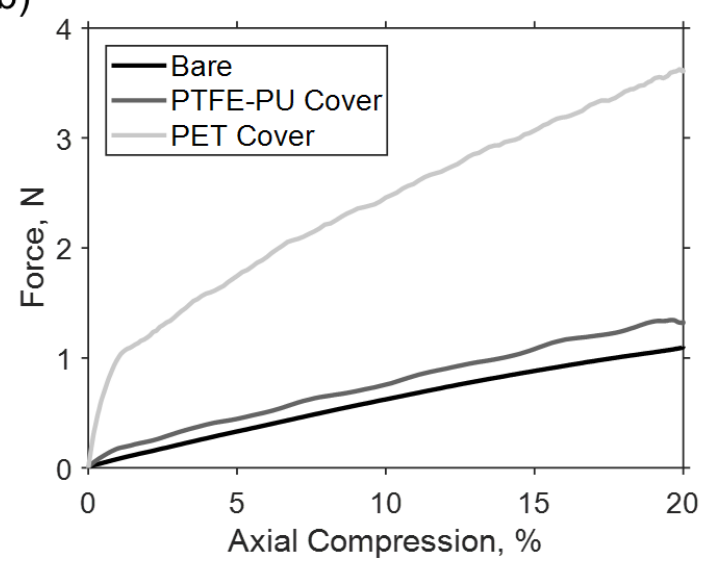

(c)

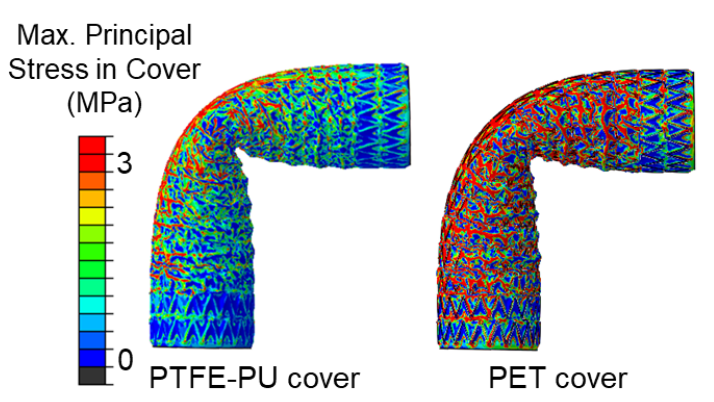

Figure 10: The effect of a stiffer polyethylene terephthalate (PET, Dacron) cover on the open-cell Precise Pro stent in terms of (a) the radial force response, (b) axial compression response, and (c) bending deformations. 


\section{Discussion}

This study investigated the biomechanical performance of bare-metal and polymer covered laser-cut stents through experimental and computational methods. Both experimental and simulated radial force testing demonstrated that the addition of a PTFE-PU polymer resulted in only modest increases in radial response at large crimp diameters, but substantial radial stiffening at small crimp diameters as the cover folded and self-contacted. It was also found that covered stents required greater force to axially compress and had a reduced cross-sectional profile under bending compared to an equivalent bare-metal stent. To accurately model the covered stent and correctly capture its mechanical behaviour, a novel covering strategy was developed which accounted for the covering manufacturing process. The computational model showed good agreement to radial, axial and bending experimental data, and was used to provide further insight into covered stent mechanical performance by considering a PET cover, as well as closed-cell and separated z-ring stent configurations. Results demonstrated that the use of a stiffer PET cover significantly altered the radial and axial response, with a six-fold increase in initial axial stiffness compared to the PTFE-PU covered stent. Additionally, it was shown that changes in interconnecting struts had significant implications in terms of deformation and stress during axial and bending loading, but a less notable effect on the radial response. Importantly, it was shown that incorporation of a thin polymer cover enables the use of disconnected metallic stent segments, to give a device with improved capability under axial compression and bending deformations. This study represents an in-depth investigation into the mechanical behaviour of bare and covered laser-cut stents and provides a robust computational model for covered stents with experimental-validation conducted under three different loading regimes.

The applicability of covered laser-cut stents has extended beyond their traditional use as stent-graft devices for aneurysm-exclusion, with attempts to utilise covered stents in small diameter vessels in the peripheral [36], coronary [37] and biliary [38] systems. In theory, covered stents promise reduced restenosis [12], with the cover acting as a mechanical barrier to tissue in-growth, yet this doesn't consistently translate into reliable clinical outcomes in small-diameter applications [39]. While numerous clinical studies have investigated the superiority of bare-metal or covered stents $[13,14,16,40]$, relatively few experimental or computational studies have attempted to explain the mechanical implication of stent covering to give more context to this problem [26-28]. Previously, it was shown that the addition of thin polymer covers to wire braided stents resulted in substantially stiffer radial and axial responses (up to ten-fold for a $25 \mu \mathrm{m}$ cover) [28]. The experimental results presented in this study show that covering an open-cell Precise Pro stent (Cordis Endovascular, a Johnson \& Johnson company, Miami, FL) with a $25 \mu \mathrm{m}$ PTFE-PU cover has minimal effects on the radial response with relatively unchanged RRF and COF values up to crimp diameters of $3 \mathrm{~mm}$. While this PTFE-PU cover is relatively compliant $(\mathrm{E}=91 \mathrm{MPa}$ ), we still observed substantial increases in max radial force when the device was crimped to $2 \mathrm{~mm}$ diameter, which could have implications in deliverability and crimping onto a catheter. The computational model showed that this is a result of the cover folding in the space between the metallic struts, which caused large amounts of self-contact and contact with the stent. For the stiffer PET-based cover (E = 910MPa), the initial radial and axial stiffness increased by $5 \%$ and $487 \%$ respectively compared to the PTFE-PU covered stent. Here it was found that cover stiffness has a more notable effect on the initial axial response since stiffening of gaps between the metallic stent frame 
increases the resistance to axial compression. To advance the development of covered stents and explain the variations in clinical outcomes, further insight is required on the mechanical implication of stent covering and its associated design considerations.

Bare and covered versions of different stent geometries were analysed to determine the combined effect of the stent frame and the cover. Under radial compression, the open-cell stent resulted in the highest forces as the interconnecting struts were circumferentially aligned and therefore provided greater resistance to crimping. There was little difference in the radial response of the closed-cell and separated z-ring stents because here, the axially-aligned interconnecting struts in the closed-cell stent did not impede the radial deformation. Stent geometry had more significant effects on the axial and bending behaviour, as the interconnecting struts dictated the deformation mechanism. Under compression, the high volume of interconnecting struts in the closed-cell stent generated a stiff axial response where the stent bulged radially outwards to accommodate deformation, generating high stress concentrations (Figure 8). Meanwhile, compression deformation in the separated z-rings stent was accommodated almost entirely by folding of the cover, so the device was axially compliant and stresses were small. Stent covering had less influence on the open-cell stent than the closed-cell stent, because the cover could fold and buckle as opposed to the large amounts of stretch required to deform the closed-cell stent. The capability of a stent to retain its lumen cross-sectional area upon bending is particularly important for applications in the dynamic femoropopliteal arteries, where there are large amounts of bending [41] and stent kinking is considered pre-emptive to vessel occlusion [42]. In Figure 9, the only stent configuration that did not exhibit some degree of kinking was the covered separated z-rings stent. Additionally, it was shown that stress in the covered separated z-ring stent was significantly lower compared to that in the open-cell and closed-cell stents, suggesting a lower likelihood of stent fracture. Interestingly, this is in line with clinical data, where three-year stent fracture rates are only $2.3 \%$ with the Viabahn Endoprosthesis (W.L. Gore and Associates, Flagstaff, Arizona), an ePTFE-covered device composed of separate z-rings, compared to $50 \%$ in a traditional bare-metal stent [43].

This study presents a novel computational method to simulate the covering process for self-expanding laser-cut stents. The main limitations of this paper relate to the large number of different covered stent configurations that exist and the range of manufacturing techniques that are used in industry. This paper focuses on the impact of covering stents with a thin polymer, but it should be acknowledged that there are many other variables concerning structural aspects of the polymer cover like cover thickness, the manufacturing process (electrospun, weaved, knitted) and the adhesion method (dip-coated, sutured), which would affect the overall functional behaviour. It is important to acknowledge that the stents experimentally tested in this study were covered by a wrapping process, and therefore the novel computational covering technique may not be relevant for covered stents which are adhered through other processes (e.g. suturing). Existing computational models of covered stents generally use an idealised cylindrical shell membrane with perfect bonding assumed between the stent and cover through a tie constraint $[29,32,44,45]$ or no-slip contact $[46,47]$. However, this study found that an idealised cylindrical cover with stent-cover bonding resulted in over-prediction of the radial and axial stiffness. The mechanical behaviour of the covered stent was better captured by accounting for the experimental cover geometry where inner and outer polymer layers were vacuumed onto the stent frame in a sandwich configuration. A similar study on covered laser-cut stent configurations for 
tracheobronchial applications has also highlighted the importance of precisely capturing the stentcover interaction around the hinges in the stent frame to accurately predict radial responses [26]. The differences observed with different covering strategies in Figure 5 further demonstrate how the covering technique itself could influence the subsequent functional performance of the device. Given the range of possible manufacturing techniques available, careful consideration should be given to modelling approach chosen to predict cover response.

\section{Conclusions}

This study presented the role of a polymer cover on the biomechanical performance of self-expanding laser-cut stents through experimental and computational methods. Experimental benchtop testing was carried out on bare and covered versions of the open-cell Precise Pro stent (Cordis Endovascular, a Johnson \& Johnson company, Miami, FL) and a computational model with a novel covering strategy was developed to accurately capture the mechanical performance of bare and polymer-covered stent systems. The computational model was further used to consider several stent designs and the effect of a stiffer polymer cover. In general, it was found that the addition of a polymer cover increased the radial and axial stiffness in all stent geometries considered. It was demonstrated that interconnecting stent segments can have a negative effect on stent flexibility and cause large increases in axial stiffness, however, an alternative solution is a covered stent with separated z-rings to provide improved flexibility without compromising radial force.

\section{Acknowledgements}

Funding support was provided by the Irish Research Council (IRC) postgraduate scholarship (GOIPG/2017/2096) and the National University of Ireland Galway Hardiman scholarship. The authors wish to acknowledge the DJEI/DES/SFI/HEA Irish Centre for High-End Computing (ICHEC) for the provision of computational facilities and support, and Aran Biomedical (Spiddal, Galway) for covering the Precise Pro stent analysed in this study. 


\section{References}

1. World Health Organization. The top 10 causes of death. 2018. https://www.who.int/newsroom/fact-sheets/detail/the-top-10-causes-of-death.

2. van Beusekom HMM, Serruys PW. Drug-Eluting Stent Endothelium. Presence or Dysfunction. JACC: Cardiovascular Interventions 2010; 3(1):76-77. doi:10.1016/j.jcin.2009.10.016.

3. Tosaka A, Soga Y, Iida $\mathrm{O}$, et al. Classification and clinical impact of restenosis after femoropopliteal stenting. Journal of the American College of Cardiology 2012. doi:10.1016/j.jacc.2011.09.036.

4. Alfonso F, Pérez-Vizcayno MJ, Cárdenas A, et al. A randomized comparison of drug-eluting balloon versus everolimus-eluting stent in patients with bare-metal stent-in-stent restenosis: The RIBS $\mathrm{v}$ clinical trial (restenosis intra-stent of bare metal stents: Paclitaxel-eluting balloon vs. everolimuselutin. Journal of the American College of Cardiology 2014; 63(14):1378-1386. doi:10.1016/j.jacc.2013.12.006. 5. Inoue T, Node K. Molecular basis of restenosis and novel issues of drug-eluting stents. Circulation journal : official journal of the Japanese Circulation Society 2009; 73(4):615-21.

6. Scheinert D, Scheinert S, Sax J, et al. Prevalence and Clinical Impact of Stent Fractures After Femoropopliteal Stenting. Journal of the American College of Cardiology 2005; 45:312-315. doi:10.1016/j.jacc.2004.11.026.

7. Maleckis K, Anttila E, Aylward P, et al. Nitinol Stents in the Femoropopliteal Artery: A Mechanical Perspective on Material, Design, and Performance. Annals of Biomedical Engineering 2018; 46(5):684-704. doi:10.1007/s10439-018-1990-1.

8. Farhatnia Y, Tan A, Motiwala A, Cousins BG, Seifalian AM. Evolution of covered stents in the contemporary era: clinical application, materials and manufacturing strategies using nanotechnology. Biotechnology advances 2013; 31(5):524-42. doi:10.1016/j.biotechadv.2012.12.010.

9. Bajaj S, Parikh R, Hamdan A, Bikkina M. Covered-Stent Treatment of Coronary Aneurysm after Drug-Eluting Stent Placement: Case Report and Literature Review. Texas Heart Institute Journal 2010; 37(4):449.

10. Wang C, Wei H, Li Y. Comparison of fully-covered vs partially covered self-expanding metallic stents for palliative treatment of inoperable esophageal malignancy: a systematic review and metaanalysis. BMC Cancer 2020; 20(1):73. doi:10.1186/s12885-020-6564-6.

11. Lansky AJ, Yang Y, Khan Y, et al. Treatment of Coronary Artery Perforations Complicating Percutaneous Coronary Intervention With a Polytetrafluoroethylene-Covered Stent Graft. The American Journal of Cardiology 2006; 98(3):370-374. doi:10.1016/J.AMJCARD.2006.02.041.

12. Satler LF, Muntz G. The promise of the covered stent. Catheterization and Cardiovascular Interventions 1999; 46(4):466. doi:10.1002/(SICI)1522-726X(199904)46:4<466::AID-CCD18>3.0.CO;2-C.

13. Lammer J, Zeller T, Hausegger KA, et al. Heparin-Bonded Covered Stents Versus Bare-Metal Stents for Complex Femoropopliteal Artery Lesions The Randomized VIASTAR Trial (Viabahn Endoprosthesis With PROPATEN Bioactive Surface [VIA] Versus Bare Nitinol Stent in the Treatment of Long Lesions in Supe. Journal of the American College of Cardiology 2013; 62:1320-1327. doi:10.1016/j.jacc.2013.05.079.

14. Hajibandeh S, Hajibandeh S, Antoniou SA, Torella F, Antoniou GA. Covered vs uncovered stents for aortoiliac and femoropopliteal arterial disease: A systematic review and meta-analysis. Journal of Endovascular Therapy 2016; 23(3):442-452. doi:10.1177/1526602816643834. 
15. Vartanian SM, Johnston PC, Walker JP, et al. Clinical consequence of bare metal stent and stent graft failure in femoropopliteal occlusive disease. Journal of Vascular Surgery 2013; 58(6):1525-1531. doi:10.1016/j.jvs.2013.05.094.

16. Mwipatayi BP, Thomas S, Wong J, et al. A comparison of covered vs bare expandable stents for the treatment of aortoiliac occlusive disease. Journal of Vascular Surgery 2011; 54(6):1561-1570.e1. doi:10.1016/J.JVS.2011.06.097.

17. Marin ML. Effect of polytetrafluoroethylene covering of palmaz stents on the development of intimai hyperplasia in human iliac arteries. Journal of Vascular and Interventional Radiology 1996; 7(5):651656. doi:10.1016/S1051-0443(96)70823-0.

18. Mwipatayi BP, Sharma S, Daneshmand A, et al. Durability of the balloon-expandable covered versus bare-metal stents in the Covered versus Balloon Expandable Stent Trial (COBEST) for the treatment of aortoiliac occlusive disease. Journal of Vascular Surgery 2016; 64(1):83-94.e1. doi:10.1016/j.jvs.2016.02.064.

19. Chang RW, Goodney PP, Baek JH, Nolan BW, Rzucidlo EM, Powell RJ. Long-term results of combined common femoral endarterectomy and iliac stenting/stent grafting for occlusive disease. Journal of Vascular Surgery 2008; 48(2):362-367. doi:10.1016/j.jvs.2008.03.042.

20. Ohki T, Kichikawa K, Yokoi H, et al. Outcomes of the Japanese multicenter Viabahn trial of endovascular stent grafting for superficial femoral artery lesions. Journal of Vascular Surgery 2017; 66(1):130-142.e1. doi:10.1016/J.JVS.2017.01.065.

21. Auricchio F, Conti M, De Beule M, De Santis G, Verhegghe B. Carotid artery stenting simulation: From patient-specific images to finite element analysis. Medical Engineering E Physics 2011; 33:281-289. doi:10.1016/j.medengphy.2010.10.011.

22. De Bock S, Iannaccone F, De Santis G, et al. Our capricious vessels: The influence of stent design and vessel geometry on the mechanics of intracranial aneurysm stent deployment. Journal of Biomechanics 2012; 45(8):1353-1359. doi:10.1016/j.jbiomech.2012.03.012.

23. Kastrati A, Mehilli J, Dirschinger J, et al. Intracoronary Stenting and Angiographic Results. Circulation 2001; 103(23):2816-2821. doi:10.1161/01.cir.103.23.2816.

24. García A, Peña E, Martínez MA. Influence of geometrical parameters on radial force during self-expanding stent deployment. Application for a variable radial stiffness stent. Journal of the mechanical behavior of biomedical materials 2012; 10:166-75. doi:10.1016/j.jmbbm.2012.02.006.

25. Farhatnia Y, Pang JH, Darbyshire A, Dee R, Tan A, Seifalian AM. Next generation covered stents made from nanocomposite materials: A complete assessment of uniformity, integrity and biomechanical properties. Nanomedicine: Nanotechnology, Biology, and Medicine 2016; 12(1):1-12. doi:10.1016/j.nano.2015.07.002.

26. McGrath DJ, O'Brien B, Bruzzi M, et al. Evaluation of cover effects on bare stent mechanical response. Journal of the Mechanical Behavior of Biomedical Materials 2016; 61:567-580. doi:10.1016/J.JMBBM.2016.04.023.

27. McKenna CG, Vaughan TJ. An experimental evaluation of the mechanics of bare and polymercovered self-expanding wire braided stents. Journal of the Mechanical Behavior of Biomedical Materials 2020; 103:103549. doi:10.1016/J.JMBBM.2019.103549. 
28. McKenna CG, Vaughan TJ. A finite element investigation on design parameters of bare and polymer-covered self-expanding wire braided stents. Journal of the Mechanical Behavior of Biomedical Materials 2021; 115:104305. doi:10.1016/j.jmbbm.2020.104305.

29. Demanget N, Avril S, Badel P, et al. Computational comparison of the bending behavior of aortic stent-grafts. Journal of the Mechanical Behavior of Biomedical Materials 2012; 5(2):272-282. doi:10.1016/j.jmbbm.2011.09.006.

30. Kleinstreuer C, Li Z, Basciano CA, Seelecke S, Farber MA. Computational mechanics of Nitinol stent grafts. Journal of Biomechanics 2008; 41(11):2370-2378. doi:10.1016/j.jbiomech.2008.05.032.

31. De Bock $S$, Iannaccone $F$, De Beule $M$, et al. Filling the void: A coalescent numerical and experimental technique to determine aortic stent graft mechanics. Journal of Biomechanics 2013; 46(14):2477-2482. doi:10.1016/J.JBIOMECH.2013.07.010.

32. Perrin D, Demanget N, Badel P, et al. Deployment of stent grafts in curved aneurysmal arteries: toward a predictive numerical tool. International Journal for Numerical Methods in Biomedical Engineering 2015; 31(1):e02698. doi:10.1002/cnm.2698.

33. Singh C, Wong C, Wang X. Medical Textiles as Vascular Implants and Their Success to Mimic Natural Arteries. Journal of Functional Biomaterials 2015; 6(3):500-525. doi:10.3390/jfb6030500.

34. Auricchio F, Taylor RL. Shape-memory alloys: modelling and numerical simulations of the finite-strain superelastic behavior. Computer Methods in Applied Mechanics and Engineering 1997; 143(12):175-194. doi:10.1016/S0045-7825(96)01147-4.

35. Aref-Azar A, Biddlestone F, Hay JN, Haward RN. The effect of physical ageing on the properties of poly(ethylene terephthalate). Polymer 1983; 24(10):1245-1251. doi:https://doi.org/10.1016/0032-3861(83)90053-8.

36. Venturini M, Marra P, Colombo M, et al. Endovascular Repair of 40 Visceral Artery Aneurysms and Pseudoaneurysms with the Viabahn Stent-Graft: Technical Aspects, Clinical Outcome and MidTerm Patency. CardioVascular and Interventional Radiology 2018; 41. doi:10.1007/s00270-017-1844-5.

37. Panduranga P, Riyami A, Riyami M, Al-Mukhaini M, Sulaiman K, Deeb M. Coronary perforation and covered stents: An update and review. Heart Views 2011; 12(2):63. doi:10.4103/1995705x.86017.

38. Conio M, Mangiavillano B, Caruso A, et al. Covered versus uncovered self-expandable metal stent for palliation of primary malignant extrahepatic biliary strictures: a randomized multicenter study. Gastrointestinal Endoscopy 2018; 88(2):283-291.e3. doi:10.1016/j.gie.2018.03.029.

39. Humphries MD, Armstrong E, Laird J, Paz J, Pevec W. Outcomes of covered versus bare-metal balloon-expandable stents for aortoiliac occlusive disease. Journal of Vascular Surgery 2014; 60(2):337344. doi:10.1016/j.jvs.2014.02.055.

40. Isayama H, Komatsu $\mathrm{Y}$, Tsujino $\mathrm{T}$, et al. A prospective randomised study of "covered" versus "uncovered" diamond stents for the management of distal malignant biliary obstruction. Gut 2004; 53(5):729-34. doi:10.1136/GUT.2003.018945.

41. MacTaggart JN, Phillips NY, Lomneth CS, et al. Three-dimensional bending, torsion and axial compression of the femoropopliteal artery during limb flexion. Journal of Biomechanics 2014; 47(10):22492256. doi:10.1016/J.JBIOMECH.2014.04.053. 
42. Cochennec F, Becquemin JP, Desgranges P, Allaire E, Kobeiter H, Roudot-Thoraval F. Limb Graft Occlusion Following EVAR: Clinical Pattern, Outcomes and Predictive Factors of Occurrence. European Journal of Vascular and Endovascular Surgery 2007; 34(1):59-65. doi:10.1016/j.ejvs.2007.01.009.

43. Geraghty PJ, Mewissen MW, Jaff MR, Ansel GM. Three-year results of the VIBRANT trial of VIABAHN endoprosthesis versus bare nitinol stent implantation for complex superficial femoral artery occlusive disease. Journal of Vascular Surgery 2013; 58(2):386-395.e4. doi:10.1016/J.JVS.2013.01.050.

44. Vad S, Eskinazi A, Corbett T, McGloughlin T, Vande Geest JP. Determination of Coefficient of Friction for Self-Expanding Stent-Grafts. Journal of Biomechanical Engineering 2010; 132(12). doi:10.1115/1.4002798.

45. Demanget N, Latil P, Orgéas L, et al. Severe Bending of Two Aortic Stent-Grafts: An Experimental and Numerical Mechanical Analysis. Annals of Biomedical Engineering 2012; 40(12):26742686. doi:10.1007/s10439-012-0618-0.

46. De Bock S, Iannaccone F, De Santis G, et al. Virtual evaluation of stent graft deployment: A validated modeling and simulation study. Journal of the Mechanical Behavior of Biomedical Materials 2012; 13:129-139. doi:10.1016/J.JMBBM.2012.04.021.

47. Gu L, Santra S, Mericle RA, Kumar A V. Finite element analysis of covered microstents. Journal of Biomechanics 2005; 38:1221-1227. doi:10.1016/j.jbiomech.2004.06.008. 